\title{
Stereotypes about Mental Health Care Providers as Predictors of Psychological Help-Seeking Intentions
}

\author{
Lasma Katsena, M.D. \\ Candidate for the Doctoral Degree at the University of Latvia, Department of Psychology \\ Iklasma@gmail.com
}

Girts Dimdins, Ph.D.

Professor of Social Psychology at the University of Latvia, Department of Psychology

\section{Doi:10.5901/mjss.2015.v6n3s2p50}

\section{Abstract}

\begin{abstract}
The aim of this study was to explore predictors of help-seeking intentions for mental health problems. This study examined warmth and competence stereotypes about mental health care providers, in relation to help-seeking intentions. A total of 338 adults participated in the study. They were asked to rate their stereotypes about psychologists, psychiatrists, family doctors, clergypersons, and astrologers, and intentions to seek help for mental health problems on a number of Likert-type scales. The results showed that the stereotypes about helping professionals in the mental health care field were significant predictors of intentions to seek help. Higher perceptions about the competence of a family doctor, psychologist, clergyman and astrologer and higher perceptions about warmth of a psychiatrist indicated potential clients' willingness to seek their help. Differences in predictors of the help-seeking intentions between different mental health care provider professions revealed a complex network of beliefs based on professional stereotypes about mental health care providers.
\end{abstract}

Keywords: stereotypes, help-seeking intentions, mental health care professionals

\section{Introduction}

Many people experience significant psychological problems in their lives; however the mental health care services are underutilised around the world. In recent years, help-seeking intentions have become a much researched topic (Gonzalez, Alegria, Prihoda, Copeland, \& Zeber, 2011; Kovess-Masféty et al., 2007; Nam et al., 2010; ten Have et al., 2010). However, this topic still involves a number of open questions. There is a lack of research addressing the role of profession stereotypes on help-seeking intentions. Therefore, the aim of this research was to explore perceived warmth and competence stereotypes about mental health care providers as predictors of help-seeking intentions for serious psychological problems.

Some researchers have found that characteristics of mental health professionals were related to attitudes toward psychological help-seeking (Cash, Kehr, \& Salzbach, 1978) and therapeutic alliance between professional and client (Alcázar Olán, Deffenbacher, Hernández Guzmán, Sharma, \& de la Chaussée Acuña, 2010; Hersoug, Høglend, Havik, von der Lippe, \& Monsen, 2009). This study focused on the role of perceived warmth and competence about mental health care providers in predicting help-seeking intentions. Warmth and competence are fundamental categories of the stereotype content model (SCM) developed by Fiske, Xu, Cuddy, and Glick (1999). The SCM has become very popular in recent studies (Bergsieker, Leslie, Constantine, \& Fiske, 2012; Brambilla, Sacchi, Castellini, \& Riva 2010; Cuddy, Fiske, \& Glick, 2007). The model provides a framework for exploring the attitudes and behaviours toward popular groups in society (Cuddy et al., 2007). People tend to approach and/or cooperate with groups perceived as warm and competent, whereas they tend to avoid and/or harm groups that are perceived as cold and incompetent. This study offers an application of this theory in a mental health care setting.

Using warmth and competence scales, Laura Bogart (2001) examined their role on health care-relevant behaviours. The results showed that the participants who perceived the physicians as more competent and warm had visited them more recently and were more satisfied with health care. As the self-rated health status was taken into account, the findings highlighted the role of perceptions of physicians on health care utilisation regardless of the need for health care. Although there was no significant relationship between stereotypes and help-seeking intentions, the study shed light on future research directions. Still the role of perceived warmth and competence stereotypes about mental 
health care providers on help-seeking intentions for mental health problems is not clear.

Little is known about the role of specific attitudes toward mental health care professionals on help-seeking intentions for psychological problems. Previous studies showed that people do not clearly differentiate between mental health care professionals, especially psychologists and psychiatrists (Firmin et al., 2012; von Sydow \& Reimer, 1998). Compared to psychologists, psychiatrists were more often viewed as cold and hostile (von Sydow \& Reimer, 1998; Wollersheim \& Walsh, 1993). Misunderstanding and misconception of mental health professions result in negative stereotypes and prejudice.

A major problem is stigmatic attitudes toward mental health care, especially psychiatric care (Sartorius et al., 2010; Schomerus, Matschinger, \& Angermeyer, 2009; Schultze, 2007; von Sydow \& Reimer, 1998). Mental illness is perceived negatively in society (Guimon, 2010). Often people with mental disorders are considered unpredictable and dangerous. Previous studies revealed that people tend to distance themselves from those with mental illness (Angermeyer \& Dietrich, 2006). Therefore, no one wants to be perceived as having a disorder or being diagnosed with it. As seeking psychological help may be misjudged by society as an indicator of having mental illness, people tend to avoid professional help and deal with mental problems on their own. Based on this, professional help-seeking may be deemed unacceptable by a substantial part of the public.

Also, the need for mental health professions is not fully understood in society. People have insufficient knowledge about mental health professions (Bremer et al., 2001; Farberman, 1997; Firmin et al., 2012). A recent study revealed surprisingly low rates of perceived effectiveness of professional mental health care (ten Have et al., 2010). Approximately one third of participants evaluated it as low or equivalent to no help. Low awareness of efficiency may facilitate underestimation of the need for psychologists and psychiatrists.

Misunderstanding, insufficient knowledge, and stigmatic perceptions about psychologists and psychiatrists could facilitate seeking help from other helping professionals. Choosing between different helping professions, many prefer to visit a family doctor in the case of serious psychological problems (Dupree, Herrera, Martinez-Tyson, Jang, \& KingKallimanis, 2010; Kovess-Masféty et al., 2007; Rickwood, Deane, Wilson, \& Ciarrochi, 2005). The profession of family doctors has a positive image among the public (Conroy, Teehan, Siriwardena, Smyth, McGee, \& Fernandes, 2002; Grol et al., 2000), and as the medical profession it is associated with status and competence (Bogart, 2001; Chang, Bair, \& Pai, 2013; von Sydow \& Reimer, 1998). In general, seeking help from this profession is not associated with the stigma of being mentally ill. Besides, the services are well-known, and usually approachable in terms of cost and transportation.

Another relevant profession in the mental health care setting is the clergyperson. Religious people are particularly likely to choose help from the representatives of this profession (Smith \& Simmonds, 2006). Similarly to psychologists, clergypersons usually are perceived as warm and caring (Schindler, Berren, Hannah, Beigel, \& Santiago, 1987), but contrary to psychologists, their help may be more approachable to the public and cost less.

Finally, although science-based and traditional professions dominate the field of mental health care, a considerable proportion of people choose to approach unconventional providers of psychological help, such as healers or astrologers, although exact figures of their popularity are not known. According to research findings, more than one third of the respondents believed in some kind of astrological principles (Rice, 2003; Robertis \& Delaney, 1993). Often astrology is attractively presented to the public; at least in Latvia, where the current study was conducted, astrology has considerable presence in mass media, where radio and TV broadcasts and magazines often publish horoscopes and feature astrologers as experts in different areas of life. Therefore we deemed it necessary to include the profession of astrologer as one of the targets in our study.

According to previous findings in studies of stereotypes, ambivalent beliefs dominate the perceived warmth and competence about mental health care providers. Medical professions, such as physicians and psychiatrists, in general are perceived as competent, but cold, whereas psychologists and clergypersons as warm, but less competent (Bogart, 2001; Schindler et al., 1987; von Sydow \& Reimer, 1998; Wollersheim \& Walsh, 1993). Based on the Stereotype Content Model (Cuddy et al., 2007; Fiske et al., 1999), a competent but cold professional in the best-case scenario would be perceived as someone with whom a person is forced to cooperate with because of serious problems, disorders or illness, and in the worst-case scenario would be seen as more harmful than helpful. On the other hand, a warm but incompetent professional in the best-case scenario would be seen as a "friend to talk to" without any real effect on problem solving, and in the worst-case scenario would just be ignored. We predicted that participants who perceive each of the five mental health care providers as higher on warmth and competence would report higher intentions to seek their help.

This study examines the role of stereotypes about psychologists, psychiatrists, family doctors, clergypersons, and astrologers regarding help-seeking intentions in the case of serious psychological problems. To our knowledge, the perception of these five helping professions has not been previously studied with the scope of measures used in the current study. Our research provides a complex view of warmth and competence stereotypes about mental health care 
providers, predicting help-seeking intentions when controlling for socio-demographic factors and past counselling for psychological problems. The study significantly expands the view of help-seeking intentions and its interpretation.

\section{Method}

\subsection{Participants}

The respondents included 338 Latvian speaking adults, aged 18 to $87(M=41.01$ years, $S D=16.25)$. There were 180 (53.3\%) women and 158 (46.7\%) men in the sample. In terms of education, 40.2\% of participants had higher education, $20.1 \%$ had unfinished higher education (including undergraduates), $37.0 \%$ had general secondary or vocational education, and $2.7 \%$ had primary education. Regarding marital status, $44.3 \%$ of respondents were not married, $37.3 \%$ were married and $18.3 \%$ were previously married (divorced or widowed). In terms of religious affiliation, $43.2 \%$ were Christians, $36.4 \%$ were not religious, $7.4 \%$ had other religious affiliation, and $13.0 \%$ did not respond to the question. The information on incomes showed that $56.2 \%$ had less than 427 euro income per household member per month (on an after-tax basis), $31.4 \%$ had equal to or greater than 427 euro, and $12.4 \%$ did not respond to this question. During the data collection (at the end of 2012 and in early 2013) average income per household member per month in Latvia was 321 euro (Central Statistical Bureau of Latvia, 2014).

\subsection{Materials}

Stereotypes. To measure warmth and competence stereotypes about mental health care providers (a psychologist, a psychiatrist, a family doctor, a clergyperson, and an astrologer) the Stereotype Content Model (SCM) (Fiske et al., 1999) was modified. It was adapted to the evaluation of professions as well as translated to Latvian. The items of warmth and competence scales were borrowed from previous research (Fiske, Cuddy, Glick, \& Xu, 2002; Russel \& Fiske, 2008). Competence items included competent, capable, and skilled, and the warmth items included kind and sincere. Participants were asked to rate a typical family doctor/ psychiatrist/ psychologist/ clergyperson/ astrologer in their opinion. The matrices of scales were given to rate each profession on warmth and competence items using a 6-point Likert-type scale, where 1 was not at all and 6 was extremely, with an additional option of "cannot tell." For each profession a short definition was provided to avoid possible misunderstandings. The reliabilities (Cronbach's alpha) for ratings of warmth were--family doctor .82, psychiatrist .87, psychologist .84, clergyperson .87, and astrologer .78; for ratings of competence--family doctor .90, psychiatrist .90, psychologist .92, clergyperson .88, and astrologer .91 .

The target professions were selected on the basis of previous literature, as well as on the basis of a series of small-scale pilot studies and lab discussions. In previous studies, exploring help-seeking intentions, mental health care providers mostly included mental health professionals (psychologists and psychiatrists); often the profession of family doctors/ physicians (see Kovess-Masféty et al., 2007; Mackenzie, Gekoski, \& Knox, 2006), and sometimes also clergypersons (e.g. Smith \& Simmonds, 2006) were included. We added the astrologer as one of the unscientific professions according to the popularity of astrology in society (Rice, 2003; Robertis \& Delaney, 1993).

Help-seeking intentions. The intentions measure was based on the instruments used in previous studies (Gonzalez et al., 2011; Mackenzie et al., 2006; ten Have et al., 2010). Participants were asked to rate their likelihood of considering seeking help from each of the five professions in the case of serious psychological problems. The ratings were made on a 4-point Likert-type scale ranging from definitely no to definitely yes. For serious psychological problems some examples were given: prolonged depressive feelings, distressing and negative thoughts, excessive nervousness/ anxiety, very conflicting relationship with close person, inability to perform daily tasks etc.

Previous service use. Participants were asked whether they have ever discussed psychological problems with each of the five professionals. The answer categories were: yes, no.

\subsection{Procedure}

Data were collected through an Internet site www.visidati.lv. The respondents were recruited via social networks. First, participants were introduced to the research. Second, they rated stereotypical characteristics of the professionals (a psychologist, a psychiatrist, a family doctor, a clergyperson, and an astrologer). After that, they completed a questionnaire about their intentions to seek help from each of the professionals. Finally, participants entered demographic information and were thanked for their participation. Informed consent has been appropriately obtained. No reward was offered for participation. 


\section{Results}

The sample size was adequate given 9 independent variables in the analysis (Tabachnick \& Fidell, 2001). The assumption of singularity was met; none of the variables were combinations of the others. Additionally, the collinearity statistics (i.e., Tolerance and VIF) were within accepted limits according to the traditional rule of thumb ${ }^{1}$ (Cohen, Cohen, West, \& Aiken, 2003).

The answer category "cannot tell" for stereotype measures was coded as missing values. Missing values ranged from $1-37$ for warmth scale and $6-34$ for competence scale. Also, they were offered the additional answer category of "I don't want to answer" for income and religion which were coded as missing values. Missing values were 42 for income and 44 for religion. The codes for socio-demographic factors are described in the note below Table 2. Descriptive statistics for ratings of warmth, competence, and help-seeking intentions are displayed in Table 1.

For each of the five professions, a step-wise regression was conducted with help-seeking intentions as the dependent variable. Socio-demographic variables and past counselling for psychological problems were entered at step one and warmth and competence were entered at step two.

Table 1. Descriptive statistics of the stereotypes and intentions to seek help from five helping professionals

\begin{tabular}{lcccccccccc}
\hline & \multicolumn{2}{c}{ Psychologist } & \multicolumn{2}{c}{ Psychiatrist } & \multicolumn{2}{c}{ Family doctor } & \multicolumn{2}{c}{ Clergyperson } & \multicolumn{2}{c}{ Astrologer } \\
\cline { 2 - 11 } & $M$ & $S D$ & $M$ & $S D$ & $M$ & $S D$ & $M$ & $S D$ & $M$ & $S D$ \\
\hline Intentions to seek help & 2.96 & .93 & 2.45 & .94 & 2.63 & 1.00 & 2.09 & .99 & 1.72 & .87 \\
Warmth & 4.33 & .98 & 3.97 & 1.11 & 4.12 & 1.05 & 4.55 & 1.04 & 4.15 & 1.05 \\
Competence & 4.32 & 1.00 & 4.33 & .97 & 4.32 & .96 & 4.34 & 1.06 & 4.15 & 1.14 \\
\hline
\end{tabular}

Note: For all five professions $n=260$ (warmth and competence), $N=338$ (help-seeking intentions)

\subsection{Psychologist}

The step-wise regression analysis revealed that at step one, socio-demographic variables and past counselling with a psychologist for psychological problems contributed significantly to the model, and accounted for $14 \%$ of the variation in intentions to seek help from a psychologist for serious psychological problems (see Table 2). Adding warmth and competence variables explained an additional $4 \%$ of the variation and the change in $\mathrm{R}^{2}$ was significant. Younger age, religiosity, past counselling and higher perceived competence of a typical psychologist were all related to higher helpseeking intentions.

\subsection{Psychiatrist}

The step-wise regression analysis showed that at step one, socio-demographic variables and past counselling with a psychiatrist for psychological problems contributed significantly to the model, and accounted for $10 \%$ of the variation in intentions to seek help from a psychiatrist (see Table 2). Introducing warmth and competence variables explained an additional $4 \%$ of the variation and the change in $\mathrm{R}^{2}$ was significant. Higher help-seeking intentions were related to past counselling and higher ratings of warmth about psychiatrist.

\subsection{Family doctor}

At step one, socio-demographic variables and past counselling with family doctor for psychological problems contributed significantly to the model, and accounted for $22 \%$ of the variation in intentions to seek help from a family doctor for serious psychological problems (see Table 2). Introducing warmth and competence variables explained an additional 3\% of the variation and the change in $\mathrm{R}^{2}$ was significant. Older age, past counselling, higher perceived competence of typical family doctor were all related to higher help-seeking intentions. At step one (before adding perceived stereotypes) gender was significantly related to higher intentions to seek help from a family doctor.

1 VIF $<10$, Tolerance $>.1$ 
Table 2. Step-wise regression analysis for help-seeking intentions from each of the five professionals in the case of serious psychological problems

\begin{tabular}{|c|c|c|c|c|c|}
\hline \multirow[b]{2}{*}{ Model variables } & \multicolumn{5}{|c|}{$\beta$} \\
\hline & $\begin{array}{c}\text { Psychologist } \\
(n=248)\end{array}$ & $\begin{array}{l}\text { Psychiatrist } \\
(n=244)\end{array}$ & $\begin{array}{c}\text { Family doctor } \\
(n=262)\end{array}$ & $\begin{array}{c}\text { Clergyperson } \\
(n=247)\end{array}$ & $\begin{array}{c}\text { Astrologer } \\
(n=237)\end{array}$ \\
\hline \multicolumn{6}{|l|}{ Step 1} \\
\hline Gender & .04 & .00 & $.12^{*}$ & .06 & $.20 * *$ \\
\hline Age & $-.18^{\star \star}$ & -.04 & $.23^{\star \star \star}$ & .04 & -.04 \\
\hline Education & .09 & .02 & -.03 & -.02 & .03 \\
\hline Religiosity & $.14^{*}$ & .12 & -.02 & $.34^{\star \star \star}$ & .00 \\
\hline Marital status & -.10 & -.11 & -.03 & -.08 & -.01 \\
\hline Income level & -.11 & .00 & .03 & -.07 & -.06 \\
\hline Past counselling for psychological problems & $.25^{\star \star \star}$ & $.30 * \star \star$ & $.36^{\star \star \star}$ & $.29 * \star \star$ & 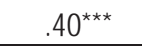 \\
\hline $\mathrm{R}^{2}$ (adjusted) & $.17(.14)$ & $.13(.10)$ & $.24(.22)$ & $.26(.24)$ & $.22(.20)$ \\
\hline $\mathrm{F}$ for $\Delta \mathrm{R}^{2}$ & $6.88^{* \star *}$ & $4.89 * \star \star$ & $11.30^{* \star *}$ & $12.25^{\star \star *}$ & $9.25^{\star \star \star}$ \\
\hline \multicolumn{6}{|l|}{ Step 2} \\
\hline Gender & .02 & -.04 & 0,09 & .02 & $.17^{\star *}$ \\
\hline Age & $-.15^{\star}$ & -.04 & 0,21 ** & .06 & -.03 \\
\hline Education & .12 & .02 & $-0,01$ & .00 & .06 \\
\hline Religiosity & $.13^{*}$ & .11 & $-0,02$ & $.30 * \star \star$ & .01 \\
\hline Marital status & -.07 & -.08 & 0,02 & -.04 & .00 \\
\hline Income level & -.08 & .01 & 0,04 & -.08 & -.04 \\
\hline Past counselling for psychological problems & $.25^{\star \star \star}$ & $.28 * \star \star$ & $0,34^{* * *}$ & $.25^{\star \star \star}$ & $.37^{\star \star \star}$ \\
\hline Warmth & -.03 & $.18^{*}$ & $-0,10$ & .09 & -.02 \\
\hline Competence & $.24^{\star \star}$ & .05 & $0,28 * *$ & $.21^{\star \star}$ & $.17^{\star}$ \\
\hline $\mathrm{R}^{2}$ (adjusted) & $.21(.18)$ & $.17(.14)$ & $.28(.25)$ & $.34(.31)$ & $.24(.21)$ \\
\hline $\mathrm{F}$ for $\Delta \mathrm{R}^{2}$ & $6.52^{* *}$ & $6.42^{\star \star}$ & $7.14^{\star \star}$ & $13.00 * * *$ & $3.23^{*}$ \\
\hline
\end{tabular}

\subsection{Clergyperson}

The step-wise regression analysis revealed that at step one, socio-demographic variables and past counselling with clergyperson for psychological problems contributed significantly to the model, and accounted for $24 \%$ of the variation in intentions to seek help from a clergyperson for serious psychological problems (see Table 2). Adding warmth and competence variables explained an additional $7 \%$ of the variation and the change in $\mathrm{R}^{2}$ was significant. Religiosity, past counselling and competence of clergyperson were all related to higher help-seeking intentions.

\subsection{Astrologer}

At step one, socio-demographic variables and past counselling with astrologer for psychological problems contributed significantly to the model, and accounted for $20 \%$ of the variation in intentions to seek help (see Table 2). Adding warmth and competence variables explained only an additional $1 \%$ of the variation, but the change in $\mathrm{R}^{2}$ was significant. Female gender, past counselling and competence of astrologer were all related to higher help-seeking intentions.

In addition to the results of the regression analysis, significant correlation coefficients should be noted. Pearson correlations were computed among socio-demographic variables, past counselling for psychological problems, stereotypes about mental health care providers and help-seeking intentions (see Table 3). 
Table 3. Correlation coefficients of help-seeking intentions from each of the five professionals in case of serious psychological problems and predictor variables

\begin{tabular}{|c|c|c|c|c|c|}
\hline \multirow{2}{*}{ Model variables } & \multicolumn{5}{|c|}{$r$} \\
\hline & Psychologist & Psychiatrist & Family doctor & Clergyperson & Astrologer \\
\hline Gender & $.18^{\star \star}$ & .06 & 0.07 & $.11^{*}$ & $.21 * \star \star$ \\
\hline Age & $-.26 * \star \star$ & .00 & $0.31^{\star \star *}$ & .05 & -.10 \\
\hline Education & .06 & .02 & $-0.11^{*}$ & -.05 & .06 \\
\hline Religiosity & $.14^{*}$ & .09 & 0.06 & $.40 * \star *$ & .07 \\
\hline Marital status & $-.17^{\star \star}$ & $-.14^{\star *}$ & $0.11^{*}$ & -.05 & -.09 \\
\hline Income level & -.02 & .01 & -0.06 & -.08 & -.03 \\
\hline Past counselling for psychological problems & $.23^{\star \star \star}$ & $.25^{\star \star \star}$ & $0.45^{\star \star \star}$ & $.36^{\star \star *}$ & $.40^{\star \star \star}$ \\
\hline Warmth & $.21 * \star \star$ & $.23^{\star \star \star}$ & $0,14^{*}$ & $.30 * \star \star$ & $.12^{\star}$ \\
\hline Competence & $.27^{\star \star \star}$ & $.21^{\star \star \star}$ & $0,25^{\star \star \star}$ & $.39 * * \star$ & $.24^{\star * *}$ \\
\hline
\end{tabular}

Note: Gender ( 0 = male, 1 = female); education ( 0 = below higher, 1 = at least started higher); religiosity $(0=$ not religious, 1 = religious); marital status $(0=$ single/divorced/widowed, $1=$ married $)$; income level $(0=$ lower to average, $1=$ above $)$; past counselling for psychological problems $(0=$ no, $1=$ yes)

For all five professions $n=294$ to 338

${ }^{*} p<.05,{ }^{* \star} p<.01,{ }^{* *} p<.001$

Additionally, Pearson correlations were computed among warmth and competence stereotypes. For all five professionals, ratings of warmth were positively correlated with ratings of competence: for psychologist $r=.72, p<.001$, for psychiatrist $r=.66, p<.001$, for family doctor $r=.77, p<.001$, for clergyperson $r=.74, p<.001$, and for astrologer $r=.59, p<.001$. Considering that warmth ratings were highly correlated with competence ratings, the regression analyses were repeated including warmth and competence in separate steps. The results of this additional analysis suggest that higher competence ratings of psychiatrist and higher warmth ratings of psychologist and clergyperson were significantly related to help-seeking intentions.

\section{Discussion}

Although predictors of help-seeking intentions have been studied before (e.g., Gonzalez et al., 2011; Kovess-Masféty et al., 2007; Nam et al., 2010; ten Have et al., 2010), a great deal of previous research has focused on socio-demographic factors and past counselling experience as predictors of intentions to seek help. The main contribution of this study was the examination of warmth and competence stereotypes about mental health care providers, in relation to help-seeking intentions in the case of mental health problems. Another contribution of this study was a comparison of mental health care professionals, psychologists and psychiatrists, with alternative mental health care providers: family doctors, clergypersons, and astrologers, for which there is a lack of previous research concerning help-seeking intentions for psychological problems.

The results of predicting help-seeking intentions from warmth and competence stereotypes are interesting. Higher perception about the warmth of a psychiatrist indicated potential clients' willingness to seek psychiatric help. Conversely, higher perceptions about the competence of the other four professions (a psychologist, a family doctor, a clergyperson, and an astrologer) indicated willingness to seek their help. Previous studies of social stereotypes have shown that stereotypes are related to specific behaviour tendencies to the stereotyped group (Cuddy et al., 2007). As the correlations showed significant relationships between both stereotypes and help-seeking intentions, it was expected that both warmth and competence would predict the intentions to seek help from all five professions. Including each stereotype dimension in a separate step in the regression analysis, results show that warmth of psychologist and clergyperson and competence of psychiatrist are significant predictors of the help-seeking intentions. However, in the two-step model when ratings of both dimensions were included in the same step of analysis, after controlling for socio-demographic variables and past counselling, only one of the stereotype dimensions predicted help-seeking intentions. Considering that warmth ratings quite highly correlated with competence ratings, this relationship might have minimised the prediction power of each separate dimension, allowing only the strongest predictor to be significant in the regression models.

Competence is a more direct measure of how capable the professional is perceived to be in regard to solving the problem or treating the person in need. Competence is expected from a professional (see Fiske et al., 2002), and, if perceived, it encourages a person to seek help, leaving the perception of warmth as less important. But for the profession of psychiatrist, the pattern was reversed. The perceived warmth of psychiatrist promotes the willingness to seek 
psychiatric help. Previous studies showed that in general psychiatrists were perceived as competent but cold compared to other mental health care professions (Schindler et al., 1987; von Sydow \& Reimer, 1998; Wollersheim \& Walsh, 1993). Although both stereotypes are important factors for the public to consider when seeking psychiatric help, the chances are that those who are not exposed to this popular negative stereotype about psychiatrists have more favourable attitudes when seeking help.

Compared to other helping professionals, psychologists and clergypersons are perceived as warmer (Schindler et al., 1987; von Sydow \& Reimer, 1998). Attribution of warmth might lead to an expectation to receive warm attitude from the professional. Conversely, previous studies have shown that medical professions are perceived as more competent but less warm (Bogart, 2001; Schindler et al., 1987; von Sydow \& Reimer, 1998). Our results suggest that, even when people consider psychological help-seeking, the perceived warmth of a family doctor is not decisive. It is possible that those who prefer to seek help from a family doctor believe that psychological problems are physical and therefore choose medical approach. Similarly, the results regarding intentions to seek help from astrologers show that only competence plays a significant role. Those respondents who prefer astrological help may believe that all life problems are determined by the stars and therefore expect from the specialist only the competence of explaining horoscopes.

Future research should explore the determinants of the stereotypes about mental health professionals and perceived acceptability of help-seeking. A better understanding of these stereotypes will help to promote help-seeking intentions and behaviour. Systematically informing the public about the available types of mental health care and about the differences between various mental health care providers, educating about the unique role of mental health care professionals, improving positive stereotypes, the effectiveness and benefits of help-seeking, as well as reducing stigma attitudes, may facilitate help-seeking intentions and behaviour.

This study had several limitations. The respondents were Latvian-speaking adults; most of them had higher education. The results cannot be generalised across the population. Future research is needed to explore the attitudes of underrepresented groups within the society. Also it should be noted that all respondents were volunteers and did not receive any reward, therefore the study does not show the attitudes of those people who chose not to participate. Because this research was focused predominantly on the intentions to seek help in case of serious psychological problems (which may affect everyone), the current mental health status of respondents was not measured in the study. But it must be taken into account that the seriousness of each individual's situation in real life could be related to the evaluation of help-seeking intentions. Although some examples of serious psychological problems were given, participants' understanding of such problems might have varied and thus influenced the results.

\section{References}

Alcázar Olán, R. J., Deffenbacher, J. L., Hernández Guzmán, L., Sharma, B., \& de la Chaussée Acuña, M. E. (2010). The impact of perceived therapist characteristics on patients decision to return or not return for more sessions. International Journal of Psychology \& Psychological Therapy, 10, 415-426.

Angermeyer, M. C., \& Dietrich, S. (2006). Public beliefs about and attitudes towards people with mental illness: A review of population studies. Acta Psychiatrica Scandinavica, 113, 163-179.

Bergsieker, H. B., Leslie, L. M., Constantine, V. S., \& Fiske, S. T. (2012). Stereotyping by omission: Eliminate the negative, accentuate the positive. Journal of Personality and Social Psychology, 102, 1214-1238.

Bogart, L. M. (2001). Relationship of stereotypic beliefs about physicians to health care-relevant behaviors and cognitions among African American women. Journal of Behavioral Medicine, 24, 573-586.

Brambilla, M., Sacchi, S., Castellini, F., \& Riva, P. (2010). The effects of status on perceived warmth and competence: Malleability of the relationship between status and stereotype content. Social Psychology, 41, 82-87.

Bremer, B. A., Foxx, R. M., Lee, M., Lykins, D., Mintz, V. R., \& Stine, E. (2001). Potential clients' beliefs about the relative competency and caring of psychologists: Implications for the profession. Journal of Clinical Psychology, 57, 1479-1488.

Cash, T. F., Kehr, J., \& Salzbach, R. F. (1978). Help-seeking attitudes and perceptions of counselor behavior. Journal of Counseling Psychology, 25, 264-269.

Chang, Y. M., Bair, H., \& Pai, J-Y. (2013). The changing image of physician in Taiwan. Asian Social Science, 9, 32-41.

Cohen, J., Cohen, P., West, S. G., \& Aiken, L. S. (2003). Applied multiple regression/correlation analysis for the behavioral sciences (3rd ed.). Hillsdale, NJ: Lawrence Erlbaum.

Conroy, R. M., Teehan, M., Siriwardena, R., Smyth, O., McGee, H. M., \& Fernandes, P. (2002). Attitudes to doctors and medicine: The effect of setting and doctor - patient relationship. British Journal of Health Psychology, 7, 117-125.

Cuddy, A. J. C., Fiske, S. T., \& Glick, P. (2007). The BIAS map: Behaviors from intergroup affect and stereotypes. Journal of Personality and Social Psychology, 92, 631-648.

Dupree, L. W., Herrera, J. R., Martinez-Tyson, D., Jang, Y., \& King-Kallimanis, B. L. (2010). Age group differences in mental health care preferences and barriers among Latinos: Implications for research and practice. Best Practices in Mental Health, 6, 47-59. 
Farberman, R. K. (1997). Public attitudes about psychologists and mental health care: Research to guide the American Psychological Association public education campaign. Professional Psychology: Research and Practice, 28, 128-136.

Firmin, M. W., Wantz, R. A., Holmes, H. J., Stoltzfus, M., Ray, B. N., \& Geib, E. F. (2012). Undergraduate college students' perceptions of psychologists. North American Journal of Psychology, 14 (2), 371-382.

Fiske, S. T., Cuddy, A. J. C., Glick, P., \& Xu, J. (2002). A model of (often mixed) stereotype content: Competence and warmth respectively follow from perceived status and competition. Journal of Personality and Social Psychology, 82, 878-902.

Fiske, S. T., Xu, J., Cuddy, A. C., \& Glick, P. (1999). (Dis)respecting versus (dis)liking: Status and interdependence predict ambivalent stereotypes of competence and warmth. Journal of Social Issues, 55(3), 473-489.

Gonzalez, J. M., Alegria, M., Prihoda, T. J., Copeland, L. A., \& Zeber, J. E. (2011). How the relationship of attitudes toward mental health treatment and service use differs by age, gender, ethnicity/race and education. Social Psychiatry and Psychiatric Epidemiology, 46, 45-57.

Grol, R., Wensing, M., Mainz, J., Jung, H. P., Ferreira, P., Hearnshaw, H., Hjortdahl, P., Olesen, F., Reis, S., Ribacke, M., Szecsenyi, J., \& European Task Force on Patient Evaluations of General Practice Care (EUROPEP) (2000). Patients in Europe evaluate general practice care: An international comparison. British Journal of General Practice, 50, 882-887.

Guimon, J. (2010). Prejudice and Realities in Stigma. International Journal of Mental Health, 39, $20-43$.

Hersoug, A. G., Høglend, P., Havik, O. E., von der Lippe, A., \& Monsen, J. T. (2009). Therapist characteristics influencing the quality of alliance in long-term psychotherapy. Clinical Psychology and Psychotherapy, 16, 100-110.

Katsena, L., \& Dimdins, G. (2013). Gender and age group differences in stereotypes about mental health care providers. Mediterranean Journal of Social Sciences, 4, 185-190.

Kovess-Masféty, V., Saragoussi, D., Sevilla-Dedieu, C., Gilbert, F., Suchocka, A., Arveiller, N., Gasquet, I., Younes, N., \& Hardy-Bayle, M-C. (2007). What makes people decide who to turn to when faced with a mental health problem? Results from a French survey. BMC Public Health, 7(188).

Mackenzie, C. S., Gekoski, W. L., \& Knox, V. J. (2006). Age, gender, and the underutilization of mental health services: The influence of help-seeking attitudes. Aging \& Mental Health, 10, 574-582.

Nam, S. K., Chu, H. J., Lee, M. K., Lee, J. K., Kim, N., \& Lee, S. M. (2010). A meta-analysis of gender differences in attitudes toward seeking professional psychological help. Journal of American College Health, 59,110-116.

Rickwood, D., Deane, F. P., Wilson, C., \& Ciarrochi, J. (2005). Young people's help-seeking for mental health problems. Australian eJournal for the Advancement of Mental Health, 4 (3) Supplement.

Rice, T. W. (2003). Believe it or not: Religious and other paranormal beliefs in the United States. Journal for the Scientific Study of Religion, 42(1), 95-106.

Robertis, M. M., \& Delaney, P. A. (1993). A survey of the attitudes of university students to astrology and astronomy. Journal of the Royal Astronomy Society of Canada, 87(1), 34-50.

Russell A. M. T, \& Fiske, S. T. (2008). It's all relative: Competition and status drive interpersonal perception. European Journal of Social Psychology, 38, 1193-1201.

Sartorius, N., Gaebel, W., Cleveland, H-R., Stuart, H., Akiyama, T., Arboleda-Florez, J., Baumann, A. J., Gureje, O., Jorge, M. R., Kastrup, M., Suzuki, Y., \& Tasman, A. (2010). WPA guidance on how to combat stigmatization of psychiatry and psychiatrists. Retrieved March 2, 2013, from http://www.wpanet.org/detail.php?section_id=7\&content_id=922

Schindler, F., Berren, M. R., Hannah, M. T., Beigel, A., \& Santiago, J. M. (1987). How the public perceives psychiatrists, psychologists, nonpsychiatric physicians, and members of the clergy. Professional Psychology: Research and Practice, 18, 371-376.

Schomerus, G., Matschinger, H., \& Angermeyer, M. C. (2009). The stigma of psychiatric treatment and help-seeking intentions for depression. European Archives of Psychiatry \& Clinical Neuroscience, 259, 298-306.

Schultze, B. (2007). Stigma and mental health professionals: A review of the evidence on an intricate relationship. International Review of Psychiatry, 19, 137-155.

Smith, A. F., \& Simmonds, J. G. (2006). Help-seeking and paranormal beliefs in adherents of mainstream religion, alternative religion, and no religion. Counselling Psychology Quarterly, 19 (4), 331-341.

Tabachnick, B. G., \& Fidell, L. S. (2001). Using multivariative statistics. 5th edition. Retrieved February 2, 2014, from http://www.scribd. com/doc/52469427/Using-Multivariate-Statistics-Barbara-Tabachnick-5th-Edition

Ten Have, M., de Graaf, R., Ormel, J., Vilagut, G., Kovess, V., Alonso, J., \& the ESEMeD/MHEDEA 2000 Investigators (2010). Are attitudes towards mental health help-seeking associated with service use? Results from the European study of epidemiology of mental disorders. Social Psychiatry and Psychiatric Epidemiology, 45, 153-163.

Von Sydow, K., \& Reimer, C. (1998). Attitudes toward psychotherapists, psychologists, psychiatrists, and psychoanalysts. A metacontent analysis of 60 studies published between 1948 and 1995. American Journal of Psychotherapy, 52, 463-488.

Wollersheim, D. M., \& Walsh, J. A. (1993). Clinical psychologists: Professionals without a role? Professional Psychology: Research and Practice, 24, 171-175. 